\title{
The feasibility of producing oil palm with altered lignin content to control ganoderma disease
}

\begin{abstract}
Oil palm is a major crop which is grown for the production of vegetable oil used in foods, cosmetics and biodiesel. The palm is of major economic importance in southeast Asia where it is grown extensively in Malaysia and Indonesia. There is concern about Ganoderma rots of oil palm which need to be controlled to prevent major infection. However, the basic mechanism of white-rot infection has been ignored. White rot implies that fungi attack the lignin component of woody tissue leaving the white cellulose exposed. The fungus grows within palms by utilizing cellulose in the tree. By altering the lignin fraction of oil palm losses may be reduced. Methods for altering lignin in plants are reviewed here to indicate how similar transformations could be attempted for oil palm. In addition, progress in transforming oil palm is described. Lignin is extremely complex and this may explain why it has not been studied in oil palm. Some crops transformed with Bacillus thuringiensis toxin genes have increased lignin and modified oil palm have been produced using B. thuringiensis genes. These require to be tested for lignin concentration and structure. The nomenclature of the disease organism is discussed. The prospects for altered lignin oil palm are considered herein.
\end{abstract}

Keyword: biofuel, biological control, disease control, evergreen tree, fungal disease, fungus, gene, infectious disease, lignin, nomenclature, toxin, vegetable oil, Bacillus thuringiensis, Elaeis, Fungi, Ganoderma, Asia, Eurasia, Indonesia, Malaysia, Southeast Asia, Ganoderma, Lignin, Oil palm, Transformations, White rot 